\title{
Iodine and differentiated thyroid cancer: Pathogenetic and therapeutic implications*
}

\author{
Smyth PPA, Cloughley GC, Clarke C, Smith DF, Burbridge E \\ UCD Conway Institute of Biomolecular and Biomedical Research, University College Dublin, Belfield, Dublin 4, \\ Ireland
}

\section{INTRODUCTION}

The purpose of this review is to discuss the various means by which iodine ingestion through dietary intake or therapeutic administration can influence the pathogenesis, prevalence, presentation or outcome of differentiated thyroid cancer (DTC). The relationship between iodine nutrition and DTC pathogenesis is complex, arising from the fundamental observation that anything that stimulates thyroid growth such as TSH, has the potential ability to promote growth and neoplastic transformation in predisposed thyroid follicular cells. ${ }^{1-3}$ One of the other major factors in the pathogenesis of thyroid cancer is previous irradiation. ${ }^{16}$ The mechanisms through which events leading to PTC are initiated is uncertain but RET/PTC rearrangements as well as RAS, PAX 8 and PPAR $\lambda$ mutations have been implicated. ${ }^{17,19}$ The sources of irradiation implicated in causing PTC have included

Key words: Iodine, Iodine Deficiency, Radioiodine Therapy, Seaweed, Thyroid Cancer

\footnotetext{
Address for correspondence:

Dr Peter Smyth, UCD Conway Institute of Biomolecular and Biomedical Research, University College Dublin, Belfield, Dublin 4, Ireland, Tel.: +353 1716 6736, Fax: +3531 7166701 E-mail ppa.smyth@ucd.ie

Received 09-05-09, Revised 20-06-09, Accepted 25-06-09
}

the consequences of the nuclear accident at Chernobyl where exposure to radioactive iodine may have been aggravated by the low dietary iodine intake in the affected population. ${ }^{20}$

\section{Iodine Intake}

Since both low and high dietary iodine intake can result in increased serum TSH, variations in dietary iodine intake can in susceptible individuals be carcinogenic. Examination of these factors has led to a diversity of findings in terms of thyroid cancer prevalence with higher rates being reported in areas of both low and high dietary iodine intake. ${ }^{2,4-8}$ There are many factors, such as ethnicity, selenium and goitrogen or carcinogen intake that complicate studies linking changes in DTC rates to iodine intake. ${ }^{3}$ Although there continues to be disagreement on whether iodine intake determines the absolute prevalence of DTC, there is strong evidence that such intake influences its form of presentation with follicular thyroid carcinoma predominating in areas of dietary iodine deficiency while the papillary form is most common where iodine intake is replete or excessive $^{5,9}$ (Table 1). Furthermore, a shift towards the papillary form occurs when a population has undergone a programme of iodine prophylaxis., ${ }^{2,10-12}$ Although the relative proportion of both follicular and anaplastic thyroid cancer declines with increas-

\footnotetext{
* Presented in part at the International Meeting on "Thyroid Cancer and Environment", 8-10 June, 2007, Santorini, Greece
} 
ing iodine intake, there are conflicting views as to whether iodine deficiency results in an increased incidence of the more aggressive histological subtypes. ${ }^{2,12,13}$ However, it should be noted that despite increased prevalence, the mortality rate for thyroid cancer has remained relatively constant, suggesting that the increases observed may reflect the use of improved diagnostic procedures revealing hitherto undetected PTC of $<1.0 \mathrm{~cm} .{ }^{2,14}$ Studies from Tasmania, while confirming the dominant finding of a higher prevalence of small $(<1.0 \mathrm{~cm})$ thyroid cancers in an iodine deficient population, also demonstrated an increase in prevalence of tumours $>1.0 \mathrm{~cm} .{ }^{15}$

\section{IODINE EXCESS}

As previously stated both excess iodine intake or a shift from lower to higher intakes has been associated with increased prevalence of PTC. ${ }^{5,10,11}$ However the picture regarding excess iodine and possible PTC induction is far from clear. In addition to its effect on thyroid function through the induction of hypothyroidism (the Wolff-Chaikhoff effect), a protective effect against the proliferation of thyroid and other cells has been attributed to excess iodine..$^{21-23}$ Iodine may exert its effect by inhibiting cAMP formation in response to stimuli perhaps through autoregulation by iodolipids such as iodolactones. ${ }^{24,25}$

Excess iodine cytotoxicity appears to reside in molecular iodine $\left(\mathrm{I}_{2}\right)$ rather than iodide $\left(\mathrm{I}^{-}\right)^{26}$ since PTU, an inhibitor of TPO and therefore of iodide organification, completely blocked iodide cytotoxicity. This mechanism appeared to involve apoptosis and may reside in the antioxidative effect of $\mathrm{I}_{2}{ }^{27,28}$ as Vitamin E deficiency, resulting in reduced antioxidative protection, significantly increases cell death. ${ }^{23}$

\section{RADIOACTIVE IODINE}

Whatever the merits of the cytotoxic properties of stable iodine, there is no question that radioactive ${ }^{131}$ I has the ability to ablate thyroid tissue. However, there is considerable debate on the therapeutic benefits of such therapy in ablating gland remnant at least in so called "low risk" PTC. ${ }^{29}$ Nevertheless, to achieve the desired ablative effect in thyroid carcinoma, it is necessary that the tumour or metastatic tissue have the ability both to accumulate radioiodide and to retain it within cells for a sufficient period. These various objectives are achieved providing that a number of preconditions as stated below can be satisfied. ${ }^{30-33}$

1. The circulating concentration of stable iodine must be low enough to permit entry of ${ }^{131} \mathrm{I}$ into cells so that competition for entry will not prevent accumulation of radioactivity in thyroid cells. In some cases this may require a low iodine diet for two weeks before administration of ${ }^{131} \mathrm{I}$.

2. The transmembrane $\mathrm{I}^{-}$transporter NIS must be

Table 1. Iodine intake and the presentation of thyroid cancer.

Thyroid Cancer and Iodine Status

Williams et al $1977^{9}$

Lower Iodine Intake (Aberdeen, Scotland)

Relatively greater prevalence of Follicular variant

Higher Iodine Intake(Iceland)

Relatively greater prevalence of Papillary variant

Change in presentation of thyroid cancer

Harach et al $1985^{14}$

Following iodine prophylaxis (Argentina; Tasmania)

Burgess et al $2002^{2}$

Increased prevalence of Thyroid Carcinoma and Papillary variant in Scotland

Reynolds et al $2005^{16}$

Ratio of Follicular and Anaplastic to Papillary Thyroid Carcinoma greater in iodine deficient regions of

Belfiore et al $1987^{17}$ Sicily

Increase in Thyroid Carcinoma in France (Mainly Papillary)

Leenhardt et al $2004^{18}$

Increased rate of thyroid cancer following the Chernobyl accident occurred in areas of low dietary iodine Robbins et al $2001^{7}$ intake 
present in sufficient amount to permit adequate ${ }^{131}$ I uptake.

3. NIS must not only be present but must be targeted to the appropriate basolateral cell membrane of the thyroid follicular cell.

4. Mechanisms to achieve retention of ${ }^{131} \mathrm{I}$, such as the enzyme thyroid peroxidase which participates in the organification of I- must be active within the thyroid cell.

\section{RESTORING NIS FUNCTION}

Many cases of cancer of the thyroid gland remnants or functioning metastases have either diminished or neglible ability to concentrate ${ }^{131}$ I. Such ${ }^{131}$ I refractoriness is often proportional to the degree of tumour dedifferentiation. ${ }^{33,34}$ Various means have been employed to promote NIS upregulation and therefore ${ }^{131}$ I uptake. These include attempts to induce endogenous NIS expression by means of cell redifferentiation or use of transgenic therapy whereby the NIS is reintroduced into cells. ${ }^{31}$ Most of the work on upregulation of NIS has been conducted on thyroid cell lines using a variety of agents such as retinoic acid or troglitazone (a PPAR- $\gamma$ analogue) $)^{35,36}$ which also inhibits cell proliferation. Other agents aim at reversing epigenetic changes in NIS DNA. These include demethylating agents such as 5-azacytidene, sodium butyrate ${ }^{37}$ or histone deacetylase inhibitors such as trichostatin A, depsipeptide or valproic acid..$^{38,39}$

Some representative aspects of attempts made in our laboratory to increase radioactive iodide, in this case ${ }^{125} \mathrm{I}$, uptake in a thyroid follicular cancer cell line (FTC133) are depicted in Figure $1 .^{40}$ This figure shows the effect on ${ }^{125}$ I uptake of incubating FTC133 cells with increasing concentrations of the histone deacetylase inhibitor trichostatin -A (TSA) over 4 hours. It can be seen that small increases in uptake (Max 40\%) were observed, achieving significance at a TSA concentration of $12.5 \mathrm{ng} / \mathrm{ml}$ but declining thereafter.

\section{IODINE IN SEAWEEDS}

The element Iodine was first discovered in seaweed by the French scientist Bernard Courtois (1811) when he treated seaweed ash with sulfuric acid. The iodine of seaweeds varies greatly between different seaweed species and, despite many years of investigation, the function of iodine and mechanism of iodide uptake in seaweeds is still unknown. What is known is the ability of seaweeds to take up iodine from seawater against a concentration gradient and, depending on the species concentrate it up to 60,000 times the concentration of this element in seawater ${ }^{41}$ (Table 2). The mechanism by which these organisms accumulate iodine is not fully understood, however, although it has been suggested that in members of the Laminaria family of seaweeds, uptake involves extracellular haloperoxidase-mediated oxidation of iodide to molecular iodine. ${ }^{42}$

The analogy between the thyroid and seaweed is based on the fact that that the relationship of the thyroid to the bloodstream is similar to that of seaweed to seawater. ${ }^{43}$ In addition to its ability to accumulate iodide by a significantly greater factor than the human thyroid, many seaweeds can retain iodide within the plant despite the presence of a large concentration gradient between the iodine rich plant $(\mathrm{mg} / \mathrm{kg})$ and the relatively iodine poor seawater $(\sim 60 \mu \mathrm{g} / \mathrm{L})$. In our study we have elaborated on the following aspects:

1. Uptake and efflux of radioactive ${ }^{125} \mathrm{I}$ by different seaweeds.

2. Chemical form in which iodine is stored within seaweeds.

3. Mechanism by which ${ }^{125} \mathrm{I}$ is taken up and stored within seaweeds.

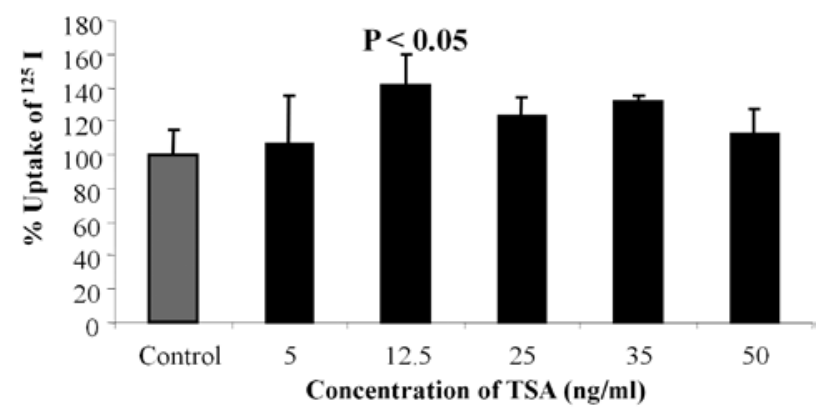

Figure 1. ${ }^{125}$ I Uptake in a human thyroid follicular cancer cell line ( FTC-133) incubated with the histone deacetylase inhibitor, Trichostatin $-\mathrm{A}$ (TSA) in various concentrations. 
4. Can understanding these mechanisms assist in improving the effectiveness of radioactive iodine ablative therapy for cancer?

\section{UPTAKE OF ${ }^{125}$ I}

Figure 2 shows the effect of incubating a variety of seaweed species for varying periods of time with ${ }^{125} \mathrm{I}$ and measuring uptake in plant tissues. The ability to accumulate ${ }^{125} \mathrm{I}$ varied with maximum uptake observed in Chondrus Crispus (Carrageen Moss) and Laminaria Digitata (Kombu). The uptake could be inhibited in a concentration dependent manner by sodium perchlorate, $(1.0 \mathrm{uM}-1.0 \mathrm{mM})$ suggesting competition for iodide transport analogous to that seen in the human thyroid. ${ }^{43}$

\section{EFFLUX OF ${ }^{125}$ I}

Loss of ${ }^{125} \mathrm{I}$ into seawater by the different seaweeds which had previously accumulated ${ }^{125} \mathrm{I}$ for $2 \mathrm{hrs}$ is shown in Figure 3. It can be seen that there was relatively little efflux $(<10 \%)$ up to 420 mins with significant loss only being observed after overnight incubation (1440 mins) which is probably the result of tissue necrosis. The level of efflux observed contrasted with that seen in a rat FRTL-5 thyroid cell line, where $85 \%$ and $95 \%$ of accumulated ${ }^{125} \mathrm{I}$ was lost at 30 and 60 mins, respectively.

\section{GENERAL COMMENTS}

Despite the absence of conclusive evidence that dietary iodine intake influences the incidence of thyroid cancer, many reports from different regions show an increasing incidence of the disease. ${ }^{1,20} \mathrm{Al}$ though much of this reported increase can no doubt be attributed to improved detection of small $(<1.0 \mathrm{~cm})$ tumours, a role for iodine intake cannot be totally excluded. ${ }^{2,20}$ The antiproliferative effects of excess iodine on thyroid cells in vitro has been reported, ${ }^{22,23}$ although the possible therapeutic relevance of such

Table 2. Iodine handling by the thyroid gland and seaweed

\begin{tabular}{ll}
\hline Thyroid gland & Seaweed \\
\hline - Takes up iodide & $\bullet$ Takes up iodide \\
- Accumulates iodide against a concentration gradient (NIS) & $\bullet$ Mechanisms of uptake and retention uncertain \\
- Concentrates iodide up to 20-40 times that & $\bullet$ Can accumulate and retain iodide against \\
of the bloodstream & a concentration gradient \\
- Organifies iodide to iodine & $\bullet$ Concentrates iodide up to 60,000 times that of the seawater \\
- Leads to formation of thyroid hormones & $\bullet$ Role of iodine in seaweed unknown \\
\hline
\end{tabular}

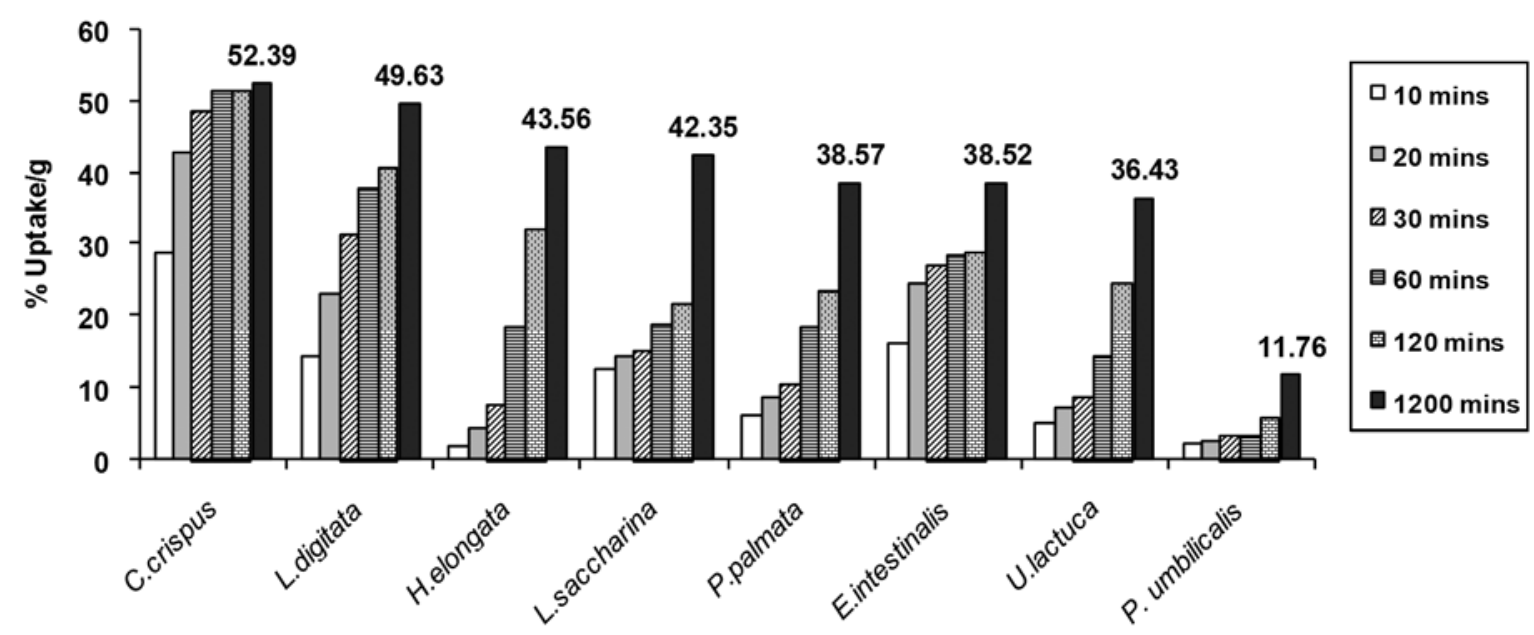

Figure 2. Uptake of ${ }^{125} \mathrm{I}$ incubated with differing seaweed species for varying times. 
findings is doubtful as in vivo administration of large amounts of iodine, apart from its possible emetic effect, would trigger an escape mechanism probably by downregulating NIS, as reported for the WolffChaikhoff effect. ${ }^{12,44}$

Unlike stable iodine, the cytotoxic effect of radioactive ablative therapy is well established. However, thyroid cancer cells when dedifferentiated often lose the ability to concentrate iodide and become refractive to radioiodine treatment. Inability to concentrate radioiodide often reflects the loss of NIS or of NIS targeting to the appropriate basolateral membrane of the thyroid follicular cell. Attempts to improve the ability of the thyroid to accumulate radioiodide have involved so called redifferentiation therapy using retinoic acid, upregulation of NIS with troglitazone (PPAR agonist) or agents aimed at reversing epigenetic modifications of NIS DNA, such as demethylation by 5-azacytidine, ${ }^{35-39}$ the histone acetylase inhibitors trichostatin, depsipeptide or valproic acid. Despite extensive studies, these approaches have only shown a modest effect, as was the case in the use of the histone acetylase inhibitor trichostatin shown in this report. Enabling cells to accumulate radioiodide is not in itself sufficient to achieve ablation. In order to achieve a cytotoxic effect, the radioisotope has to be retained within the cell for a sufficient period to enable the radiation to destroy the surrounding tis- sue. Attempts to increase ${ }^{131}$ I retention time in the thyroid have included the use of lithium salts ${ }^{45,46}$ to increase the effective biological $t_{1 / 2}$ of ${ }^{131} \mathrm{I}$.

The difficulty of promoting ${ }^{131} \mathrm{I}$ accumulation and retention by a significant proportion of thyroid cancers prompted the study of another model having properties similar to the thyroid. The model selected was seaweed which bears the same relationship to its surrounding seawater as does the thyroid to the blood circulation. Uptake of ${ }^{125}$ I into seaweeds correlated directly with their iodine content, the higher uptakes being observed in seaweeds with the greatest iodine content. Studies on ${ }^{125}$ I efflux from seaweeds showed that the species tested had a remarkable ability to retain ${ }^{125}$ I even in the presence of a large concentration gradient. The iodine content of seawater is of the order of $50-60 \mu \mathrm{g} / \mathrm{l}$ while that of seaweeds species investigated in this study is of the order of $280-5000 \mathrm{mg} / \mathrm{kg}$. ${ }^{47,48}$ The ability of the seaweed L. Digitata to retain up to $80 \%{ }^{125}$ I even after $24 \mathrm{hrs}$ incubation contrasted with that of the rat thyroid FRTL-5 cell line which lost $83 \%$ after 30 mins and $97 \%$ after $60 \mathrm{mins}$.

\section{CONCLUSIONS}

A possible role for dietary iodine intake in influencing thyroid cancer prevalence remains to

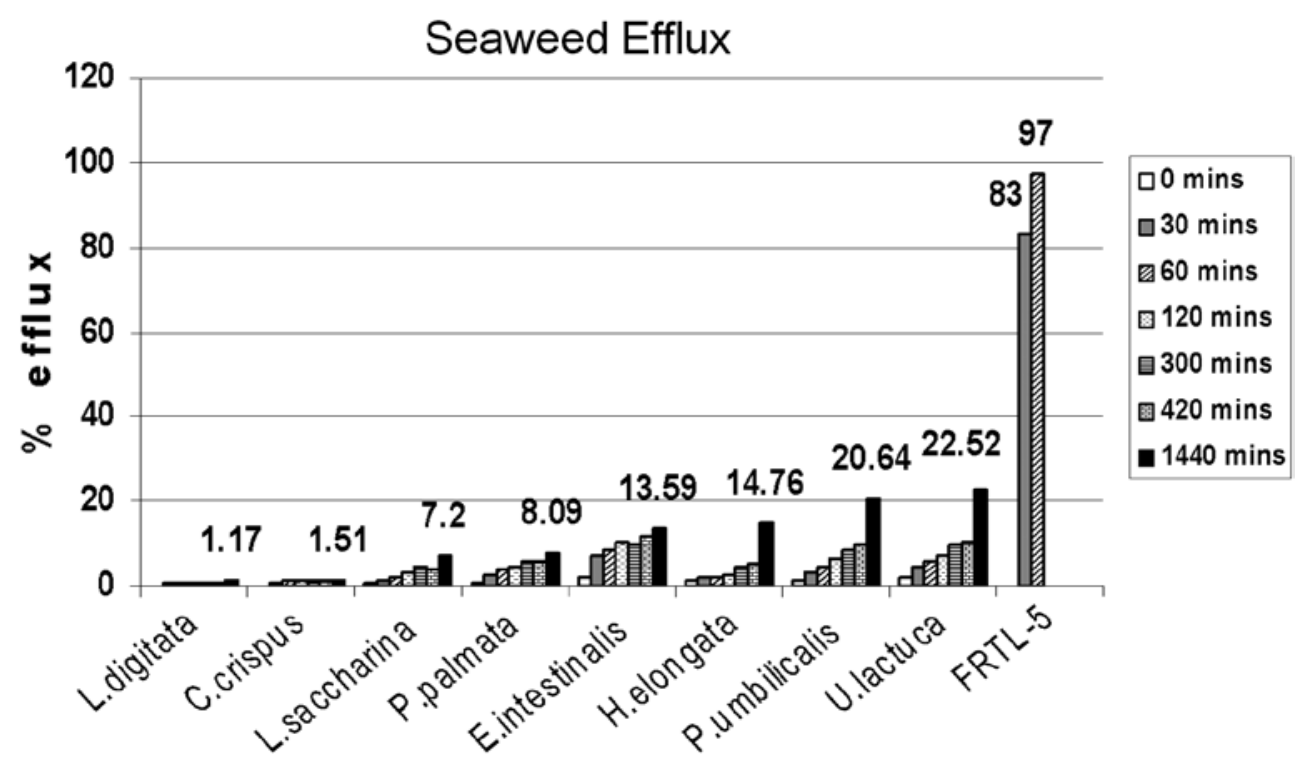

Figure 3. Efflux of ${ }^{125}$ I from differing seaweed species for varying times. Seaweeds preincubated with ${ }^{125} \mathrm{I}$ for 4 hrs. 
be elucidated. It is of course highly probable that superimposition of iodine deficiency or excess onto a thyroid already genetically susceptible to thyroid cancer or in whom a mutation, radiation insult or ingestion of a chemical carcinogen may provide a stimulus to carcinogenesis. While thyroid gland ablation by radioactive ${ }^{131} \mathrm{I}$, the adjunct treatment of choice for gland remnant or metastatic ablation, the means of restoring ${ }^{131} I$ concentrating ability lost during tumour dedifferentiation leave a lot to be desired. The same applies to methods of promoting ${ }^{131}$ I retention time within thyroid cells. The ability to accumulate and retain ${ }^{131} \mathrm{I}$ has been studied in seaweeds. The author is well aware that ion transport systems in primitive algae may be far removed from those in the mammalian thyroid. However, the properties exhibited by seaweeds, in terms of efficient uptake of iodide and in particular retentive ability, suggest that further exploration of these properties has the potential of providing some insights which may benefit the therapeutic use of radioiodine.

\section{REFERENCES}

1. Feldt-Rasmussen U, 2001 Iodine and cancer. Thyroid 11: 483-486.

2. Burgess JR, 2002 Temporal trends for thyroid carcinoma in Australia: an increasing incidence of papillary thyroid carcinoma (1982-1997). Thyroid 12:141-149.

3. Knobel M, Medeiros-Neto G, 2007 Relevance of iodine intake as a reputed predisposing factor for thyroid cancer. Arq Bras Endocrinol Metabol 51: 701-712.

4. Robbins J, Schneider AB, 2000 Thyroid cancer following exposure to radioactive iodine. Rev Endocr Metab Disord. 3: 197-203.

5. Nakazawa T, Kondo T, Kobayashi Y, et al, 2005 RET gene rearrangements (RET/PTC1 and RET/PTC3) in papillary thyroid carcinomas from an iodine-rich country (Japan).Cancer 104: 943-951

6. Nikiforova MN, Nikiforov YE, 2008 Molecular genetics of thyroid cancer: implications for diagnosis, treatment and prognosis. Expert Rev Mol Diagn 8: 83-95.

7. Robbins J, Dunn JT, Bouville A, et al, 2001 Iodine nutrition and the risk from radioactive iodine: a workshop report in the chernobyl long-term follow-up study. Thyroid. 11: 487-491.

8. Belfiore A, La Rosa GL, La Porta GA, et al, 1992 Cancer risk in patients with cold thyroid nodules: relevance of iodine intake, sex, age, and multinodularity. Am J Med 93: 363-369.

9. Williams ED, Doniach I, Bjarnason O, Michie W, 1977
Thyroid cancer in an iodide rich area: a histopathological study. Cancer 39: 215-222.

10. Franssila K, Saxén E, Teppo L, et al, 1981 Incidence of different morphological types of thyroid cancer in the Nordic countries. Acta Pathol Microbiol Scand 89: 49-55.

11. Goodman MT, Yoshizawa CN, Kolonel LN, 1988 Descriptive epidemiology of thyroid cancer in Hawaii. Cancer 61: 1272-1281.

12. Wolff J, 1989 Excess iodide inhibits the thyroid by multiple mechanisms. Adv Exp Med Biol 261: 211-264.

13. Kasagi K, 2007 Epidemiology of thyroid tumors: effect of environmental iodine intake. Nippon Rinsho 65: 1953-1958.

14. Harach HR, Escalante DA, Onativia A, Lederer Outes J, Saravia Day E, Williams ED, 1985 A study on the relationship between solid cell nests and mucoepidermoid carcinoma of the thyroid. Histopathology 9: 195-207.

15. Langsteger W, Költringer P, Wolf G, et al, 1993 The impact of geographical, clinical, dietary and radiationinduced features in epidemiology of thyroid cancer. Eur J Cancer 29: 1547-1553.

16. Reynolds RM, Weir J, Stockton DL, Brewster DH, Sandeep TC, Strachan MW, 2005 Changing trends in incidence and mortality of thyroid cancer in Scotland. Clin Endocrinol(Oxf) 62: 156-162.

17. Belfiore A, La Rosa GL, Padova G, Sava L, Ippolito O, Vigneri R, 1987 The frequency of cold thyroid nodules and thyroid malignancies in patients from an iodinedeficient area. Cancer 60: 3096-3102

18. Leenhardt L, Grosclaude P, Chérié-Challine L, Thyroid Cancer Committee, 2004 Increased incidence of thyroid carcinoma in France: a true edipemic or thyroid nodule management effects? Report from the French Thyroid Cancer Committee. Thyroid 14: 1056-1060.

19. Burgess JR, Tucker P, 2006 Incidence trends for papillary thyroid carcinoma and their correlation with thyroid surgery and thyroid fine-needle aspirate cytology. Thyroid 16: 47-53.

20. Burgess JR, Dwyer T, McArdle K, Tucker P, Shugg D 2000 The changing incidence and spectrum of thyroid carcinoma in Tasmania (1978-1998) during a transition from iodine sufficiency to iodine deficiency. J Clin Endocrinol Metab 85: 1513-1517.

21. Vitale,M, di Matola T, D'Ascoli F, et al, 2000 Iodide excess induces apoptosis in thyroid cells through a p53-independent mechanism involving oxidative stress. Endocrinology 141: 598-605.

22. Venturi S, Donati FM, Venturi A, Venturi M, Grossi L, Guidi A, 2000 Role of iodine in evolution and carcinogenesis of thyroid, breast and stomach. Adv Clin Path 4: 11-17.

23. Mutaku JF, Poma JF, Many MC, Denef JF, van Den Hove MF, 2002 Cell necrosis and apoptosis are differentially regulated during goitre development and iodine-induced involution. J Endocrinol 172: 375-386.

24. Gärtner R, Dugrillon A, Bechtner G, 1996 Evidence that 
iodolactones are the mediators of growth inhibition by iodine on the thyroid. Acta Med Austriaca 23: 47-51.

25. Dugrillon A, 1996 Iodolactones and iodoaldehydes-mediators of iodine in thyroid autoregulation. Exp Clin Endocrinol Diabetes 104: Suppl 4: 41-45.

26. García-Solís P, Alfaro Y, Anguiano B, et al, 2005 Inhibition of $\mathrm{N}$-methyl-N-nitrosourea-induced mammary carcinogenesis by molecular iodine (I2) but not by iodide (I-) treatment Evidence that I2 prevents cancer promotion. Mol Cell Endocrinol 236: 49-57.

27. Smyth PP, 2003 Role of iodine in antioxidant defence in thyroid and breast disease. Biofactors 19: 121-130.

28. Joanta AE, Filip A, Clichici S, Andrei S, Daicoviciu D, 2006 Iodide excess exerts oxidative stress in some target tissues of the thyroid hormones. Acta Physiol Hung 93: 347-359.

29. Hay ID, Thompson GB, Grant CS, et al, 2002 Papillary thyroid carcinoma managed at the Mayo Clinic during six decades (1940-1999): temporal trends in initial therapy and long-term outcome in 2444 consecutively treated patients. World J Surg 26: 879-885.

30. Dohán O, De la Vieja A, Paroder V, et al, 2003 The sodium/iodide Symporter (NIS): characterization, regulation, and medical significance. Endocr Rev 24: 48-77.

31. Riesco-Eizaguirre G, Santisteban P, 2006 A perspective view of sodium iodide symporter research and its clinical implications. Eur J Endocrinol 155: 495-512.

32. Spitzweg C, Morris JC, 2002 Sodium Iodide Symporter (NIS) and Thyroid. Hormones (Athens) 1: 22-34.

33. Kogai T, Taki K, Brent GA, 2006 Enhancement of sodium/iodide symporter expression in thyroid and breast cancer. Endocr Relat Cancer 13: 797-826.

34. Boelaert K, Smith VE, Stratford AL, 2007 PTTG and $\mathrm{PBF}$ repress the human sodium iodide symporter. Oncogene 26: 4344-4356.

35. Schmutzler C, Winzer R, Meissner-Weigl J, Köhrle J, 1997 Retinoic acid increases sodium/iodide symporter mRNA levels in human thyroid cancer cell lines and suppresses expression of functional symporter in nontransformed FRTL-5 rat thyroid cells. Biochem Biophys Res Commun 240: 832-838.

36. Park JW, Zarnegar R, Kanauchi H, et al, 2005 Troglitazone, the peroxisome proliferator-activated receptorgamma agonist, induces antiproliferation and redifferentiation in human thyroid cancer cell lines. Thyroid 15: 222-231.
37. Venkataraman GM, Yatin M, Marcinek R, Ain KB, 1999 Restoration of iodide uptake in dedifferentiated thyroid carcinoma: relationship to human $\mathrm{Na}+/ \mathrm{I}$-symporter gene methylation status. J Clin Endocrinol Metab 84: 2449-2457.

38. Kitazono M, Robey R, Zhan Z, et al, 2001 Low concentrations of the histone deacetylase inhibitor, depsipeptide (FR901228), increase expression of the $\mathrm{Na}(+) / \mathrm{I}(-)$ symporter and iodine accumulation in poorly differentiated thyroid carcinoma cells. J Clin Endocrinol Metab 86: 3430-3435.

39. Zarnegar R, Brunaud L, Kanauchi H, et al, 2001 Increasing the effectiveness of radioactive iodine therapy in the treatment of thyroid cancer using Trichostatin A, a histone deacetylase inhibitor. Surgery 132: 984-990.

40. Clarke C, Burbridge E, Smyth PPA, 2004 Deacetylating agents as mediators of iodide uptake and efflux in thyroid and breast. Endocrine Abstracts 7: P81.

41. Hou X, Yan X, Chai C, 2000 Chemical Species of iodine in some seaweeds II. Iodine-bound biological macromolecules. J Radioanal Nucl Chem 245: 461-467.

42. Kupper FC, Schweigert N, et al, 1998 Iodine Uptake. In Laminariales Involves Extracellular, HaloperoxidaseMediated Oxidation of Iodide. Planta 207: 163-171.

43. Smyth Peter 2006 Seaweed. Iodine and Health (2006) SOLAS-Ireland 1st National Report., Ed. C.D. O'Dowd, ISBN 978-0-9553862-1-3 [0-9553862-1-7]

44. Dohán O, Portulano C, Basquin C, Reyna-Neyra A, Amzel LM, Carrasco N, 2007 The Na+/I symporter (NIS) mediates electroneutral active transport of the environmental pollutant perchlorate. Proc Natl Acad Sci USA 104: 20250-20255.

45. Markou K, Georgopoulos N, Kyriazopoulou V, Vagenakis AG, 2001 Iodine-Induced hypothyroidism. Thyroid 11: 501-510.

46. Bogazzi F, Bartalena L, Pinchera A, Martino E, 2002 Adjuvant effect of lithium on radioiodine treatment of hyperthyroidism. Thyroid 12: 1153-1154.

47. Morrissey J, Kraan S, Guiry MD, 2001 A guide to commercially important seaweeds on the Irish coast. Bord Iascaigh Mhara 66: www.bim.ie

48. Teas J, Pino S, Critchley A, Braverman LE, 2004 Variability of iodine content in common commercially available edible seaweeds. Thyroid 14: 836-841. 